\title{
Local Heine-Abarenkov Potential of Alkali Metals
}

\section{$\operatorname{AUTHOR}(\mathrm{S})$ :}

SOMA, Toshinobu; SATOH, Toshio; SAKURABA, Tsutomu; YAMAHIRA, Chizuko; OHYAMA, Takakiyo

\section{CITATION:}

SOMA, Toshinobu ... [et al]. Local Heine-Abarenkov Potential of Alkali Metals. 物性研究 1978, 31(3): 181-196

ISSUE DATE:

1978-12-20

URL:

http://hdl.handle.net/2433/89741

RIGHT: 


\title{
Local Heine-Abarenkov Potential of Alkali Metals
}

Toshinobu SOMA, Toshio SATOH, Tsutomu SAKURABA, Chizuko YAMAHIRA and Takakiyo OHYAMA*

\author{
Department of Applied Physics and Mathematics, \\ Mining College, Akita University, \\ Akita 010, JAPAN \\ ( 1978 年 11 月 15 日受理)
}

* 相馬俊信, 佐藤敏夫, 桜庭 勉, 山平千鶴子, 大山孝清 
相馬俊信, 佐藤敏夫, 桜庭 勉, 山平千鶴子, 大山孝清

\begin{abstract}
A local Heine-Abarenkov model potential satisfying the energy minimum condition of the crystal is presented for alkali metals. The remaining parameter is determined from the first zero of the original pseudopotential by Animalu and Heine themselves using the atomic energy levels from spectroscopic data. The local Heine-Abarenkov potential obtained is noticeably different for Li from the previous models. Then, the crystal energy, pressure and bulk modulus of alkali metals are calculated and compared with the results of the previous models by other workers. The third order contributions are also investigated, and their effects are not negligible but small for alkali metals except Li.
\end{abstract}

\title{
$\S 1$. Introduction
}

The physical properties such as cohesive energy, pressure, bulk modulus and lattice dynamics of simple metals have been widely investigated from the electron theory of solids. The pseudopotential concept was proposed for the band calculation, but the perturbational treatment of pseudopotential has opened possibilities for calculating various crystal properties directly without band calculations. The so-called second order perturbation theory based on the pseudopotential formalism has been applied to simple metals with many successful examples (see for example ${ }^{1)}$ ). Thereafter, since the expression for the third order perturbation term was obtained by Lloyd-Sholl ${ }^{2)}$ and Brovman et al. ${ }^{3)}$, some works ${ }^{4-8)}$ about the third order contributions have been reported. At present, the pseudopotential formalism is applied to the anharmonicity of lattice dynamics and the problem of complicated lattice defects for simple metals, and its extension to noble and transition metals is studied intensively.

\section{§2. Local Heine-Abarenkov Potential}

\section{$\S 2.1$. Determination of the Parameter}

The pseudopotential has a nonlocal character essentially, but the local model potential is convenient and desirable, especially in the perturbational treatment. For simple metals, the typical examples with only one parameter are given in the following two types. One is the empty-core potential by Ashcroft ${ }^{9)}$ (hereafter referred to as A) in the Fourier-transform $V_{\mathrm{b}}(q)$ of the atomic pseudopotential $V_{\mathrm{b}}(r)$.

$$
V_{\mathrm{b}}(q)=-\frac{4 \pi Z e^{2}}{\Omega_{0} q^{2}} \quad \cos \left(q \cdot r_{\mathrm{c}}\right)
$$


The other is the optimized model potential by Shaw ${ }^{10)}$ given by

$$
V_{\mathrm{b}}(q)=-\frac{4 \pi Z e^{2}}{\Omega_{0} q^{2}} \frac{\sin \left(q \cdot r_{\mathrm{c}}\right)}{q \cdot r_{\mathrm{c}}}
$$

In eqs. (1) and (2), $Z$ and $\Omega_{0}$ are valency and atomic volume respectively. Then, the parameter $r_{\mathrm{c}}$ corresponds to the core radius and is determined by fitting the shape of Fermi surface or the resistivity of liquid metal in the case of Ashcroft's potential. Ashcroft and Langreth ${ }^{11)}$ introduced the extra parameter in the first order perturbation energy of the pseudopotential in order to satisfy the zero pressure condition that the total crystal energy $E$ should have the minimum at the observed crystal volume $\Omega_{0}$. Their procedure corresponds substantially to the model with two parameters. The self consistent model potential with two parameters are the local Heine-Abarenkov-type potential given by

$$
\begin{array}{rl}
V_{\mathrm{b}}(r)=\frac{Z e^{2}}{R_{\mathrm{M}}} u & r<R_{\mathrm{M}} \\
& -\frac{Z e^{2}}{r} \quad r>R_{\mathrm{M}} .
\end{array}
$$

The Fourier-transform $V_{\mathrm{b}}(q)$ of this potential is

$$
V_{\mathrm{b}}(q)=-\frac{4 \pi Z e^{2}}{\Omega_{0} q^{2}} \quad\left\{(1+u) \cos \left(q \cdot R_{\mathrm{M}}\right)-u \frac{\sin \left(q \cdot R_{\mathrm{M}}\right)}{q \cdot R_{\mathrm{M}}}\right\} .
$$

The local Heine-Abarenkov potential leads to the empty-core potential in the case of $u=0$ and the Shaw's potential in the case of $u=-1$.

Previously, five works ${ }^{12-16)}$ to determine the parameter $R_{\mathrm{M}}$ and $u$ have been reported. The form $f(q)$ in the electronic dielectric function $\epsilon(q)$, including the electronic exchange and correlation effects, is also important.

$$
\begin{aligned}
& \epsilon(q)=1+\frac{4 \pi e^{2}}{q^{2}} \frac{\chi_{0}(q)}{1-4 \pi e^{2} f(q) \chi_{0}(q) / q^{2}} \\
& \chi_{0}(q)=\frac{k_{\mathrm{F}}}{4 \pi^{2}}\left\{1+\frac{1-\left(q / 2 k_{\mathrm{F}}\right)^{2}}{q / k_{\mathrm{F}}} \ln \left|\frac{1+q / 2 k_{\mathrm{F}}}{1-q / 2 k_{\mathrm{F}}}\right|\right\}
\end{aligned}
$$


相馬俊信, 佐藤敏夫, 桜庭 勉, 山平千鶴子, 大山孝清

where $k_{\mathrm{F}}$ is Fermi wave number. $\mathrm{Ho}^{12)}$ used the modified Hubbard-type ${ }^{17)} f(q)=q^{2} / 2\left(q^{2}+\right.$ $\xi k_{\mathrm{F}}^{2}$ ). Three parameters $R_{\mathrm{M}}, u$ and $\xi$ were determined by satisfying three elastic constants $C_{11}, C_{44}$ and $C^{\prime}=\left(C_{11}-C_{12}\right) / 2$. Afterwards, considering the importance of the zero-pressure condition, $\mathrm{Ho}^{13)}$ (referred to as m.Ho) corrected these parameters. Brovman et al. ${ }^{14)}$ (referred to as B-K-K) obtained the parameter $\xi$ to satisfy the compressibility sum rule of an electron gas, and $R_{\mathrm{M}}, u$ by fitting the elastic constants $C_{44}$ and the zero-pressure condition. Popovic et al. $\left.{ }^{15}\right)$ (referred to as P-C-P) adopted $f(q)=A\left\{1-\mathrm{e}^{-B\left(q / k_{\mathrm{F}}\right)^{2}}\right\}$ obtained by Singwi et al. ${ }^{18)}$. Parameters $A$ and $B$ depend on the electron density and give the compressibility sum rule of an electron gas. Parameters $R_{\mathrm{M}}$ and $u$ were determined by fitting the bulk modulus $B=\left(C_{11}+\right.$ $\left.2 C_{12}\right) / 3$ and the stable condition for the uniform volume expansion. Senoo et al. ${ }^{16)}$ used the Hubbard-Sham approximation ${ }^{19)}$ for $f(q)$. This corresponds to the parameter $\xi=1+2 / \pi k_{\mathrm{F}}$ and violates largely and fatally the compressibility sum rule of an electron gas for the low density elements such as alkali metals. Consequently, we omit the model by Senoo et al. in what follows.

In determining the parameters of the model potential, we feel that the zero-pressure condition is necessary in order to maintain the stability of the crystal structure, and that the data of Fermi surface and atomic properties should be used as far as possible. The bulk modulus, elastic constants and phonon dispersion curves should be the physical properties to try the model potential in comparison with observed data. Therefore in the present work, using the first zero $V_{\mathrm{b}}\left(q_{0}\right)=0$ of the original Heine-Abarenkov potential ${ }^{20)}$ (referred to as $\mathrm{A}-\mathrm{H}$ ), we obtain the following relation

$$
u=\frac{q_{0} R_{\mathrm{M}} \cos \left(q_{0} R_{\mathrm{M}}\right)}{\sin \left(q_{0} R_{\mathrm{M}}\right)-q_{0} R_{\mathrm{M}} \cos \left(q_{0} R_{\mathrm{M}}\right)} .
$$

The first zero $q_{0}$ of the Fourier-transform $V_{\mathrm{b}}(q)$ are shown in Table I in comparison with Table I. The first zero $q_{0} / 2 k_{\mathrm{F}}$ of the pseudopotential form factor $V_{\mathrm{b}}(q)$ for various models.

$\begin{array}{lcccccc} & \text { A-H } & \text { A } & \text { Ho } & \text { m.Ho } & \text { B-K-K } & \text { P-C-P } \\ \mathrm{Li} & 0.77 & 1.26 & 1.12 & 1.08 & - & 1.02 \\ \mathrm{Na} & 0.89 & 0.97 & 0.98 & 1.00 & 0.92 & 0.90 \\ \mathrm{~K} & 0.89 & 0.93 & 0.93 & 0.90 & 0.88 & 0.90 \\ \mathrm{Rb} & 0.97 & 0.82 & 0.94 & 0.91 & - & 0.92 \\ \mathrm{Cs} & 0.96 & 0.79 & - & 0.90 & - & 0.92\end{array}$


those by others. We notice that the value of $\mathrm{Li}$ deviates largely from other data. The remaining one parameter is determined by satisfying the zero-pressure condition in the framework of the usual second order perturbation given by

$$
\left.\frac{d E}{d \Omega}\right|_{\Omega=\Omega_{0}}=0
$$

In performing numerical calculations, we adopt the following four approximations to the exchange correction $f(q)$ to the dielectric screening function $\epsilon(q)$. First, the modified Hubbardtype (referred to as $\mathrm{H}$ ). Secondly, Kleinman-Langreth-type ${ }^{21)}$ (referred to as K-L) $f(q)=$ $q^{2} / 4\left(q^{2}+\xi k_{\mathrm{F}}^{2}\right)+q^{2} / 4 \xi k_{\mathrm{F}}^{2}$ where the parameter $\xi$ is obtained from the compressibility sum rule of an electron gas with Nozières-Pines formula ${ }^{22}$ ) for the correlation energy. Thirdly, the one by Singwi et al. (referred to as S-S-T-L), and lastly, the revised one by Vashishta-Singwi ${ }^{23}$ ) (referred to as V-S).

\section{$\S 2.2$. Numerical Results}

The values of $R_{\mathrm{M}}$ and $u$ determined by the procedure of eqs. (7) and (8) are summarized in Table II compared with the previous works. In our model, the pseudopotential of Li re-

Table II. Parameters $R_{\mathrm{M}}$ (in atomic unit) and $u$ of the local Heine-Abarenkov-type model potential for various models.

\begin{tabular}{|c|c|c|c|c|c|c|c|c|c|c|}
\hline & \multicolumn{4}{|c|}{ present work } & \multirow{2}{*}{$\mathrm{Ho}$} & \multirow{2}{*}{$\begin{array}{c}\mathrm{m} . \mathrm{Ho} \\
\mathrm{H}\end{array}$} & \multirow{2}{*}{$\begin{array}{c}\text { B-K-K } \\
\mathrm{H}\end{array}$} & \multirow{2}{*}{$\frac{\text { P-C-P }}{\text { S-S-T-L }}$} & \multirow{2}{*}{$\mathrm{A}-\mathrm{H}^{*}$} \\
\hline & & $\mathrm{H}$ & K-L & S-S-T-L & V-S & & & & & \\
\hline $\mathrm{Li}$ & $\begin{array}{l}R_{\mathrm{M}} \\
u\end{array}$ & $\begin{array}{l}1.384 \\
0.6885\end{array}$ & $\begin{array}{l}1.406 \\
0.6292 \\
\end{array}$ & $\begin{array}{l}1.409 \\
\quad 0.6214 \\
\end{array}$ & $\begin{array}{l}1.408 \\
0.6240\end{array}$ & $\begin{array}{r}2.230 \\
-0.9421 \\
\end{array}$ & $\begin{array}{c}1.68 \\
-0.5863 \\
\end{array}$ & $\longrightarrow$ & $\begin{array}{r}1.560 \\
-0.3730 \\
\end{array}$ & $\begin{array}{c}2.8 \\
-0.941\end{array}$ \\
\hline $\mathrm{Na}$ & $\begin{array}{l}R_{\mathrm{M}} \\
u\end{array}$ & \begin{tabular}{|c}
2.047 \\
-0.2722 \\
\end{tabular} & $\begin{array}{c}2.073 \\
-0.2965 \\
\end{array}$ & $\begin{array}{c}2.072 \\
-0.2956 \\
\end{array}$ & $\begin{array}{c}2.085 \\
-0.3074 \\
\end{array}$ & $\begin{array}{r}2.305 \\
-0.6246 \\
\end{array}$ & $\begin{array}{c}2.40 \\
-0.6840 \\
\end{array}$ & $\begin{array}{r}2.073 \\
-0.363 \\
\end{array}$ & $\begin{array}{c}2.076 \\
-0.3079 \\
\end{array}$ & $\begin{array}{c}3.4 \\
-1.037 \\
\end{array}$ \\
\hline $\mathrm{K}$ & $\begin{array}{l}R_{\mathrm{M}} \\
u\end{array}$ & $\begin{array}{c}3.019 \\
-0.5682 \\
\end{array}$ & $\begin{array}{c}3.050 \\
-0.5825 \\
\end{array}$ & $\begin{array}{r}3.049 \\
-0.5821 \\
\end{array}$ & $\begin{array}{r}3.037 \\
-0.5766 \\
\end{array}$ & $\begin{array}{r}3.005 \\
-0.6205 \\
\end{array}$ & $\begin{array}{c}3.04 \\
-0.5761 \\
\end{array}$ & $\begin{array}{r}2.973 \\
-0.540 \\
\end{array}$ & $\begin{array}{r}3.035 \\
-0.5723 \\
\end{array}$ & $\begin{array}{c}4.2 \\
-1.008 \\
\end{array}$ \\
\hline $\mathrm{Rb}$ & $\begin{array}{l}R_{\mathrm{M}} \\
u\end{array}$ & $\begin{array}{c}3.980 \\
-0.9047 \\
\end{array}$ & $\begin{array}{c}4.018 \\
-0.9140 \\
\end{array}$ & $\begin{array}{r}4.039 \\
-0.9191 \\
\end{array}$ & $\begin{array}{c}3.973 \\
-0.9030 \\
\end{array}$ & $\begin{array}{r}3.288 \\
-0.6592 \\
\end{array}$ & $\begin{array}{c}3.54 \\
-0.7115 \\
\end{array}$ & & $\begin{array}{r}3.553 \\
-0.7273 \\
\end{array}$ & $\begin{array}{c}4.4 \\
-0.985 \\
\end{array}$ \\
\hline Cs & $\begin{array}{l}R_{\mathrm{M}} \\
u\end{array}$ & $\begin{array}{c}4.610 \\
-0.9605\end{array}$ & $\begin{array}{c}4.711 \\
-0.9818\end{array}$ & $\begin{array}{c}4.790 \\
-0.9982\end{array}$ & $\begin{array}{c}4.804 \\
-1.0012\end{array}$ & - & $\begin{array}{l}3.95 \\
-0.7367\end{array}$ & - & $\begin{array}{c}4.114 \\
-0.8079\end{array}$ & $\begin{array}{c}4.8 \\
-0.984\end{array}$ \\
\hline
\end{tabular}

*We adopt $u$ of $\mathrm{s}$ electrons for the nonlocal Animalu-Heine pseudopotential.

presents the repulsive interaction inside the core, but this fact does not mean unphysical result because even the negative values of $u$ are varied widely in various models given by Table 
相馬俊信, 佐藤敏夫, 桜庭 勉, 山平千鶴子, 大山孝清

II. The sign of $u$ depends on the sign of the factor $F=\tan \left(q_{0} R_{\mathrm{M}}\right) / q_{0} R_{\mathrm{M}}-1$. The negative $u$ is obtained when $\pi / 2<q_{0} R_{\mathrm{M}}<4.49$. This condition corresponds to $2.04<R_{\mathrm{M}}<5.83$ for Li in our model, but we have no energy-minimum point actually within this region of $R_{\mathrm{M}}$. The full curves of the screened pseudopotential form factor $V_{\mathrm{s}}(q)=V_{\mathrm{b}}(q) / \epsilon(q)$ thus obtained are shown in Figs. 1-5, for $\mathrm{Li}, \mathrm{Na}, \mathrm{K}, \mathrm{Rb}$ and $\mathrm{Cs}$, respectively. In figures, we show the results (full line) including the V-S exchange correction. Then, the results with the common V-S

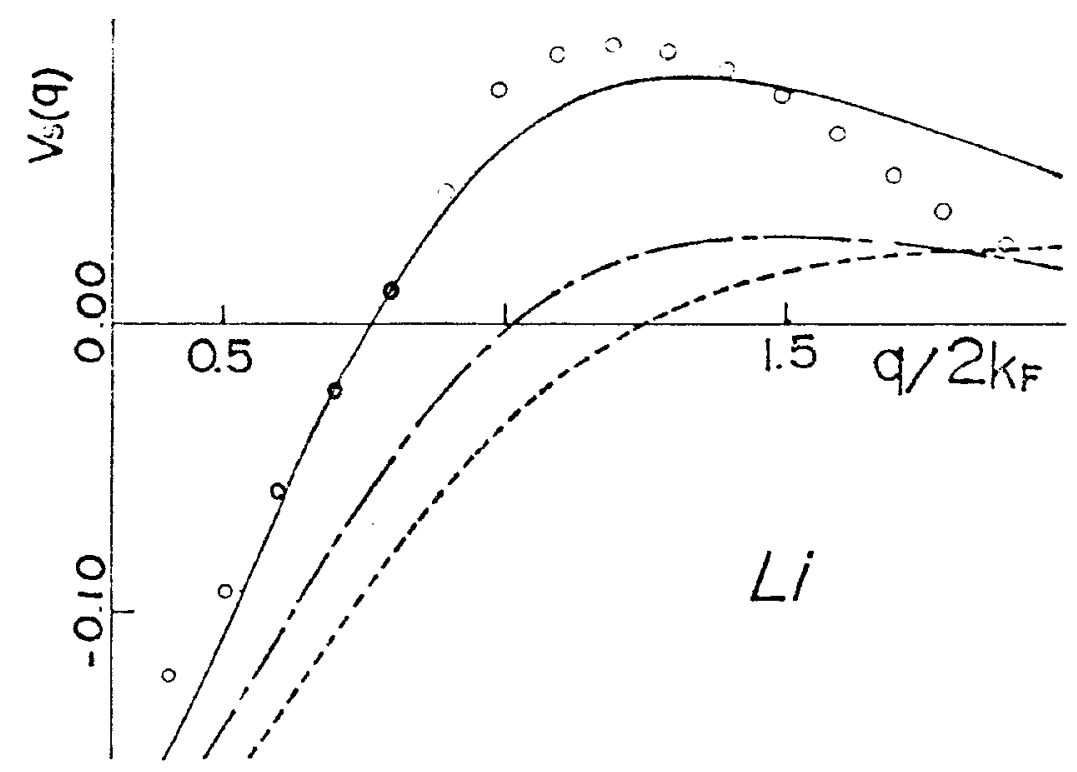

Fig. 1

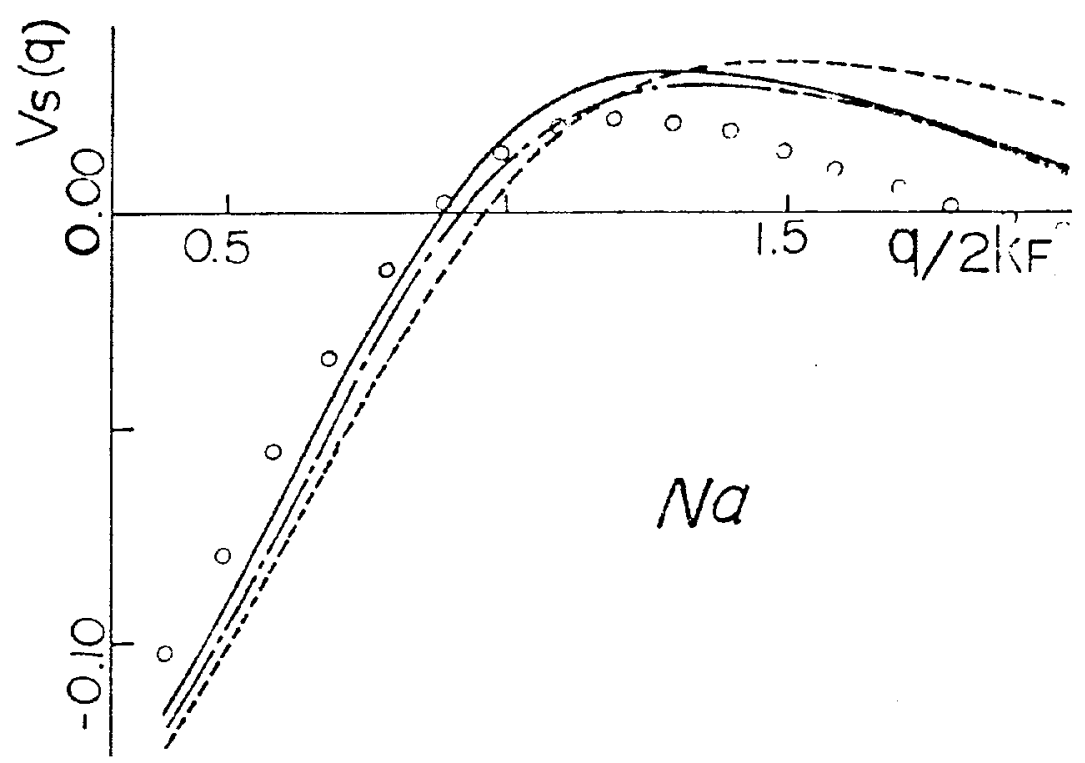

Fig. 2 
Local Heine-Abarenkov Potential of Alkali Metals

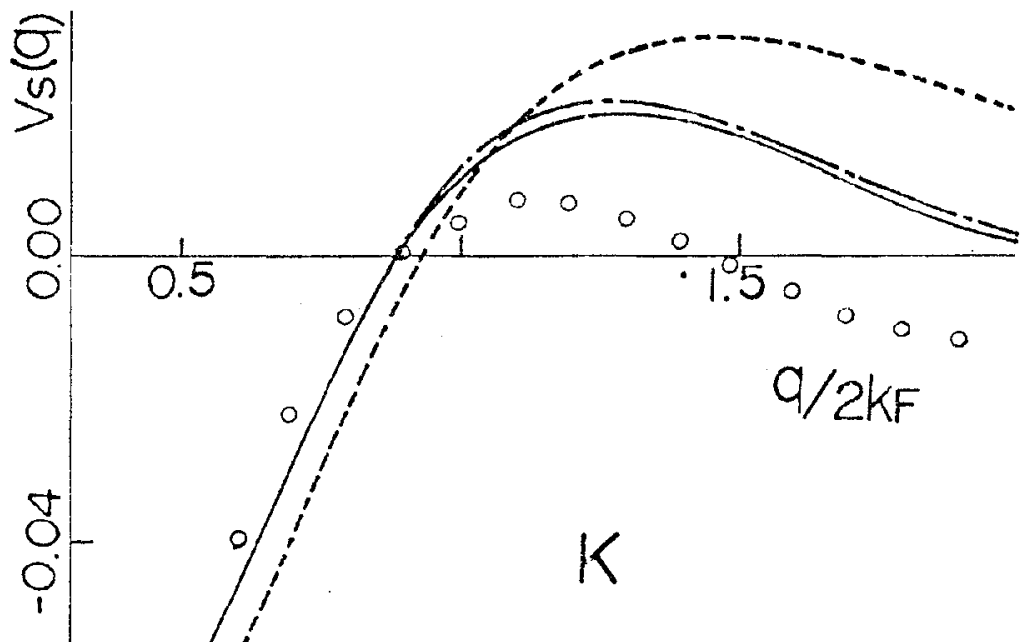

Fig. 3

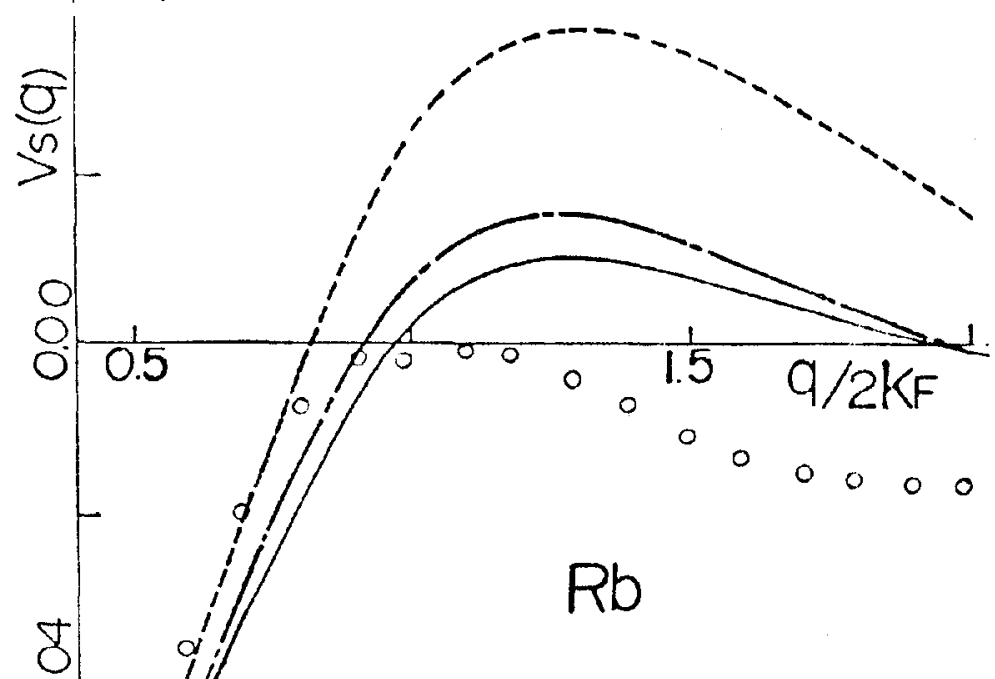

Fig. 4

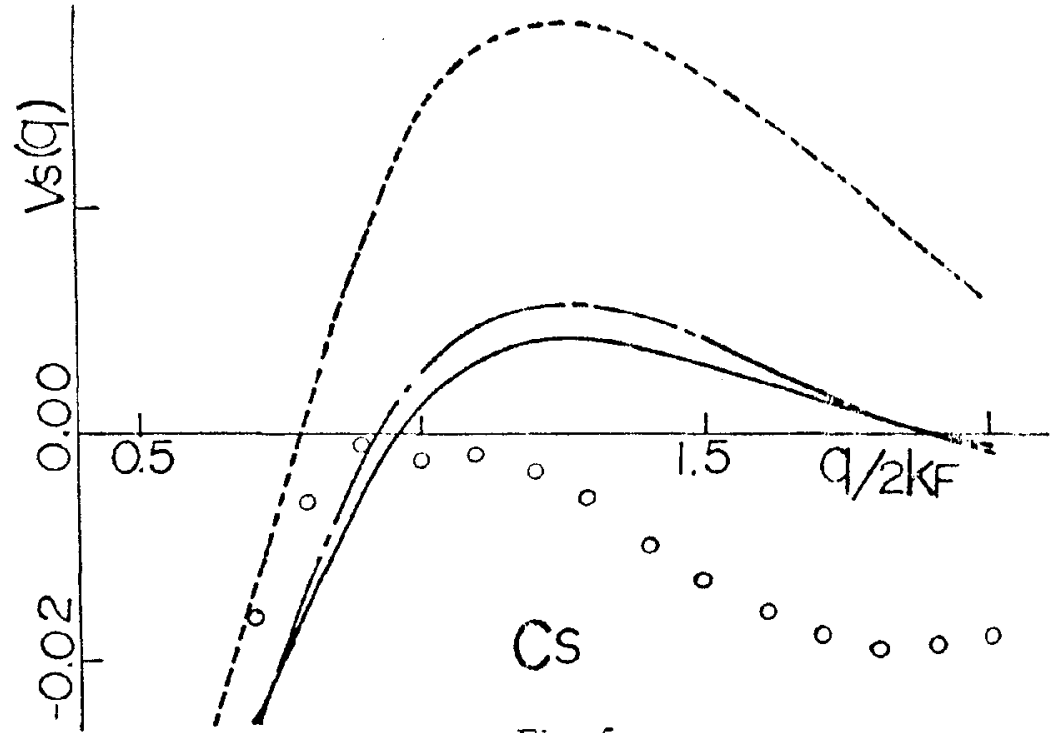

Fig. 5 
相馬俊信, 佐藤敏夫, 桜庭 勉, 山平千鶴子, 大山孝清

exchange correction by P-C.P (chain line) and by A potential (broken line), and A-H potential (points) are shown together. The notable difference between the local Heine-Abarenkov potential and the empty-core potential is that the latter shows the oscillation with the large amplitude in the region of $q>2 k_{\mathrm{F}}$. As a whole, our local Heine-Abarenkov potential is quite different for $\mathrm{Li}$ from the previous models by others. In Table III, we give the first three pseu-

Table III. The screened pseudopotential Fourier component $V_{\mathrm{s}}(G)$ (in Rydberg unit).

\begin{tabular}{|c|c|c|c|c|c|c|c|c|c|c|}
\hline & \multicolumn{4}{|c|}{ present work } & \multirow{2}{*}{$\frac{\mathrm{Ho}}{\mathrm{H}}$} & \multirow{2}{*}{$\frac{\mathrm{m} . \mathrm{Ho}}{\mathrm{H}}$} & \multirow{2}{*}{$\frac{\mathrm{B}-\mathrm{K}-\mathrm{K}}{\mathrm{H}}$} & \multirow{2}{*}{$\begin{array}{r}\text { P-C-P } \\
\text { S-S-T-L }\end{array}$} & \multirow{2}{*}{$\frac{A}{V-S}$} & \multirow{2}{*}{$\mathrm{A}-\mathrm{H}$} \\
\hline & $\mathrm{H}$ & $\mathrm{K}-\mathrm{L}$ & S-S-T-L & V-S & & & & & & \\
\hline $\operatorname{Li} V_{\mathbf{S}}(100)$ & 0.0758 & 0.0799 & 0.0783 & 0.0788 & 0.0020 & 0.0066 & & $0.0162-$ & -0.0121 & 0.0935 \\
\hline$V_{\mathrm{S}}(200)$ & 0.0754 & 0.0760 & 0.0742 & 0.0744 & 0.0104 & 0.0199 & & 0.0285 & 0.0212 & 0.0611 \\
\hline$V_{\mathrm{s}}(211)$ & 0.0531 & 0.0518 & 0.0506 & 0.0508 & 0.0042 & 0.0127 & & 0.0193 & 0.0252 & 0.0164 \\
\hline$\dot{\mathrm{Na}} V_{\mathrm{s}}(110)$ & 0.0282 & 0.0302 & 0.0294 & 0.0297 & 0.0137 & 0.0125 & 0.0231 & 0.0287 & 0.0229 & 0.0200 \\
\hline$V_{\mathrm{S}}(200)$ & 0.0282 & 0.0284 & 0.0278 & 0.0274 & 0.0158 & 0.0138 & 0.0248 & 0.0273 & 0.0346 & 0.0089 \\
\hline$V_{S}(211)$ & 0.0146 & 0.0140 & 0.0138 & 0.0133 & 0.0062 & 0.0046 & 0.0128 & 0.0135 & 0.0265 & -0.0038 \\
\hline $\begin{array}{ll}\mathrm{K} & V_{\mathrm{S}}(110) \\
\end{array}$ & 0.0179 & 0.0195 & 88 & 5 & 45 & 0.0178 & 0.0187 & 0.0191 & 0.0225 & 0.0073 \\
\hline$V_{\mathrm{S}}(200)$ & 0.0130 & 0.0132 & 0.0127 & 0.0130 & 0.0121 & 0.0126 & 0.0138 & 0.0131 & 0.0293 & -0.0055 \\
\hline$V_{\mathrm{s}}(211)$ & 0.0027 & 0.0023 & 0.0022 & 0.0024 & 0.0030 & 0.0023 & 0.0032 & 0.0024 & 0.0211 & -0.0116 \\
\hline $\mathrm{Rb} V_{\mathrm{s}}(110)$ & 0.0082 & 0.0090 & 0.0086 & 0.1 & 25 & 33 & & 0.0135 & 0.0349 & -0.0015 \\
\hline$V_{s}(200)$ & 0.0053 & 0.0055 & 0.0052 & 0.0055 & 0.0103 & 0.0080 & & 0.0080 & 0.0298 & -0.0146 \\
\hline$V_{\mathrm{s}}(211)$ & -0.0002 & -0.0003 & -0.0003 & -0.0002 & 0.0022 & 0.0000 & & 0.0000 & 0.0159 & -0.0172 \\
\hline $\operatorname{Cs} V_{s}(110)$ & 0.0075 & 0.0084 & 0.0080 & 0.0 & 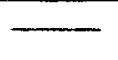 & 0.0122 & & 0.0109 & 0.0358 & -0.0025 \\
\hline$V_{\mathrm{S}}(200)$ & 0.0042 & 0.0044 & 0.0042 & 0.0043 & & 0.0066 & & 0.0055 & 0.0275 & -0.0160 \\
\hline$V_{\mathrm{S}}(211)$ & -0.0005 & -0.0005 & -0.0005 & -0.0005 & 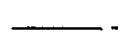 & -0.0006 & 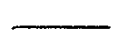 & -0.0008 & 0.0129 & -0.0179 \\
\hline
\end{tabular}

dopotential Fourier component $V_{s}(G)$ compared with those by previous models. The close examination of our presented model potential is tried by applying to calculations of the cohesive energy and bulk modulus in the following section.

\section{§3. Cohesive Energy and Bulk Modulus}

\section{$\S 3.1$. Second Order Perturbation Scheme}

In the framework of the usual second order perturbation based on pseudopotentials, the total energy $E$ per atom in metallic crystals is given as follows:

$$
E=E_{i}+E^{(0)}+E^{(1)}+E^{(2)} .
$$

$E_{i}$ is the Madelung energy that means the total Coulomb energy of positively charged ions in a uniformly negatively charged background. $E^{(0)}$ is the energy of the free electron gas consisting of the kinetic, exchange and correlation energies. $E^{(1)}$ is the first order perturba- 
tion energy in terms of pseudopotentials and in our model with the local Heine-Abarenkov potential it becomes

$$
E^{(1)}=\frac{2 \pi Z e^{2}}{\Omega_{0}} R_{\mathrm{M}}^{2}\left(1+\frac{2 u}{3}\right)
$$

$E^{(2)}$ is the second order term usually called as the band-structure energy.

$$
E^{(2)}=-\frac{\Omega_{0}}{2} \sum_{G \neq 0} \frac{V_{\mathrm{b}}(G)^{2}}{\epsilon(G)} \frac{\chi_{0}(G)}{1-4 \pi e^{2} f(G) \chi_{0}(G) / G^{2}}
$$

The pressure $P$ and the bulk modulus $B$ are obtained from the first and the second derivative of the crystal energy with respect to the crystal volume $\Omega_{0}$ as follows:

$$
\begin{aligned}
& P=-\frac{d E}{d \Omega_{0}}, \\
& B=\Omega_{0} \frac{d^{2} E}{d \Omega^{2}{ }_{0}} .
\end{aligned}
$$

We divide the pressure and the bulk modulus into four contributions in the same way as the crystal energy in eq. (9) and write

$$
\begin{aligned}
& P=P_{i}+P^{(0)}+P^{(1)}+P^{(2)} \\
& B=B_{i}+B^{(0)}+B^{(1)}+B^{(2)}
\end{aligned}
$$

In Tables IV-VIII, we show the obtained results of the crystal energy, the cohesive energy, the pressure and the bulk modulus for alkali metals compared with those by previous models. In these tables the small deviations from the results of the previous works are due to the small difference of the lattice constants. We must examine critically the cohesive energy in order to avoid the superficial agreement of the total energy. From Table IV, we see that our value of the cohesive energy is better agreement with the observed data compared with those by the previous workers, especially for Li. We do not introduce the fitting the elastic constants and the bulk modulus, but our results for the bulk modulus is in good agreement with the experiments shown in Table V. In Table VI-VIII, we show the individual terms in 
相馬俊信, 佐藤敏夫, 桜庭 勉, 山平千鶴子, 大山孝清

Table IV. The total crystal energy $E$ per atom (in Rydberg unit) and the cohesive energy $E_{\mathrm{coh}}$ (in $\mathrm{eV}$ unit).

\begin{tabular}{|c|c|c|c|c|c|c|c|c|c|c|}
\hline$E$ & & present & work & & Ho & m.Ho & B-K-K & P-C-P & $\mathrm{A}-\mathrm{L}^{*}$ & obs.** \\
\hline & $\mathrm{H}$ & K-L & S-S-T-L & V-S & $\mathrm{H}$ & $\mathrm{H}$ & $\mathrm{H}$ & S-S-T-L & V-S & - \\
\hline & -0.5370 & -0.5367 & -0.5333 & -0.5290 & -0.5411 & -0.5542 & & -0.5469 & -0.5512 & -0.5162 \\
\hline $\mathrm{Ja}$ & -0.4637 & -0.4631 & -0.4608 & -0.4553 & -0.4688 & -0.4664 & -0.4678 & -0.4612 & -0.4501 & -0.4598 \\
\hline & -0.3893 & -0.3890 & -0.3867 & -0.3822 & -0.3964 & -0.3884 & -0.3902 & -0.3868 & -0.3733 & -0.3878 \\
\hline$b$ & -0.3704 & -0.3701 & -0.3676 & -0.3637 & -0.3780 & -0.3670 & & -0.3664 & -0.3481 & -0.3700 \\
\hline & -0.3458 & -0.3455 & -0.3430 & -0.3384 & 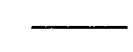 & -0.3437 & & -0.3424 & -0.3283 & -0.3451 \\
\hline & & & & & & & & & & \\
\hline $\mathrm{Li}$ & 1.91 & 1.91 & 1.86 & 1.80 & 1.97 & 2.15 & & 2.05 & 2.11 & 1.63 \\
\hline & 1.166 & 1.158 & 1.127 & 1.052 & 1.236 & 1.203 & 1.222 & 1.132 & 0.982 & 1.113 \\
\hline & 0.955 & 0.950 & 0.919 & 0.858 & 1.051 & 1.121 & 0.967 & 0.921 & 0.737 & 0.934 \\
\hline & 0.857 & 0.853 & 0.819 & 0.764 & 0.961 & 0.811 & & 0.803 & 0.554 & 0.852 \\
\hline & 0.813 & 0.809 & 0.775 & 0.712 & - & 0.784 & & 0.767 & 0.575 & 0.804 \\
\hline
\end{tabular}

*We obtained the results by Ashcroft-Langreth' ${ }^{11)}$ procedure with Ashcroft's empty-core potential ${ }^{9}$. **From data collected by $\mathrm{Kittel}^{24}$ ).

Table V. The bulk modulus $B$ (in $10^{11} \mathrm{dyn} \cdot \mathrm{cm}^{-2}$ unit).

\begin{tabular}{lcccccccccc}
$B$ & \multicolumn{4}{c}{ present work } & \multicolumn{1}{c}{ Ho } & m.Ho & B-K-K & P-C.P & A-L & obs.* \\
& $\mathrm{H}$ & K-L & S-S-T-L & V-S & H & H & H & S-S-T-L & V-S & - \\
$\mathrm{Li}$ & 1.373 & 1.371 & 1.262 & 1.246 & 1.297 & 1.308 & - & 1.324 & 1.183 & $1.410,1.320$ \\
$\mathrm{Na}$ & 0.807 & 0.794 & 0.718 & 0.699 & 0.766 & 0.746 & 0.743 & 0.753 & 0.742 & $0.790,0.760$ \\
$\mathrm{~K}$ & 0.385 & 0.395 & 0.358 & 0.348 & 0.376 & 0.368 & 0.378 & 0.366 & 0.315 & 0.366 \\
$\mathrm{Rb}$ & 0.306 & 0.322 & 0.283 & 0.285 & 0.264 & 0.290 & - & 0.282 & 0.311 & $0.277,0.306$ \\
$\mathrm{Cs}$ & 0.266 & 0.282 & 0.239 & 0.245 & - & 0.217 & - & 0.213 & 0.243 & 0.231
\end{tabular}

*From data collected by Soma ${ }^{25}$.

eqs.(9), (14) and (15) contributing to the total energy, the pressure and the bulk modulus, respectively. From these tables, we obtain the following predominant characteristics. First, the contributions from the electron system become important when going from the total energy to the bulk modulus. In the extreme case for the bulk modulus of $\mathrm{Li}$ in our model, the second order term of the pseudopotential contributes almost as much as the electrostatic term between ions. Secondly, the model by Ashcroft-Langreth give large contributions of the second order term because of the long range character of the model potential with the large oscillation, and the agreement with the experimental data, especially for the cohesive energy is not good. Thirdly, in our model, the pseudopotential of $\mathrm{Li}$ is large and the contributions 
from the electron system are important with respect to the higher order perturbations.

Table VI. The individual terms $E_{i}, E^{(0)}, E^{(1)}$ and $E^{(2)}$ contributing to the total energy (in Rydberg unit).

\begin{tabular}{|c|c|c|c|c|c|c|c|}
\hline & & present* & A-L* & Ho & m.Ho & B-K-K & P-C-P \\
\hline \multirow[t]{4}{*}{$\mathrm{Li}$} & $E_{i}$ & -0.5515 & & & & & \\
\hline & $E^{(0)}$ & -0.1447 & & -0.1510 & & & -0.1495 \\
\hline & $E^{(1)}$ & 0.2458 & 0.1533 & 0.1629 & 0.1503 & & 0.1599 \\
\hline & $E^{(2)}$ & -0.0783 & -0.0083 & -0.0003 & -0.0020 & $\longrightarrow$ & -0.0058 \\
\hline \multirow[t]{4}{*}{$\mathrm{Na}$} & $E_{i}$ & -0.4557 & & & & & \\
\hline & $E^{(0)}$ & -0.1556 & & -0.1625 & & & -0.1605 \\
\hline & $E^{(1)}$ & 0.1705 & 0.1770 & 0.1530 & 0.1546 & 0.1607 & 0.1690 \\
\hline & $E^{(2)}$ & -0.0145 & -0.0158 & -0.0035 & -0.0028 & -0.0102 & -0.0140 \\
\hline \multirow[t]{4}{*}{$\mathrm{K}$} & $E_{i}$ & -0.3684 & & & & & \\
\hline & $E^{(0)}$ & -0.1537 & & -0.1608 & & & -0.1588 \\
\hline & $E^{(1)}$ & 0.1481 & 0.1677 & 0.1381 & 0.1484 & 0.1475 & 0.1486 \\
\hline & $E^{(2)}$ & -0.0081 & -0.0189 & -0.0052 & -0.0076 & -0.0084 & -0.0081 \\
\hline \multirow[t]{4}{*}{$\mathrm{Rb}$} & $E_{i}$ & -0.3447 & & & & & \\
\hline & $E^{(0)}$ & -0.1513 & & -0.1583 & & & -0.1561 \\
\hline & $E^{(1)}$ & 0.1342 & 0.1825 & 0.1294 & 0.1407 & & 0.1389 \\
\hline & $E^{(2)}$ & -0.0018 & -0.0345 & -0.0044 & -0.0046 & & -0.0044 \\
\hline \multirow[t]{4}{*}{$\mathrm{Cs}$} & $E_{i}$ & -0.3184 & & & & & \\
\hline & $E^{(0)}$ & -0.1473 & & & -0.1554 & & -0.1520 \\
\hline & $E^{(1)}$ & 0.1292 & 0.1775 & - & 0.1337 & & 0.1315 \\
\hline & $E^{(2)}$ & -0.0018 & -0.0400 & $\longrightarrow$ & -0.0045 & 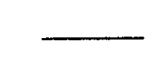 & -0.0033 \\
\hline
\end{tabular}

*We adopt V-S approximation for the exchange correction. 
相馬俊信, 佐藤敏夫, 桜庭 勉, 山平千鶴子, 大山孝清

Table VII. The individual terms $P_{i}, P^{(0)}, P^{(1)}$ and $P^{(2)}$ contributing to the pressure (in $10^{10} \mathrm{dyn} \cdot \mathrm{cm}^{-2}$ ).

\begin{tabular}{|c|c|c|c|c|c|c|c|}
\hline & & present & A-L & Ho & $\mathrm{m} . \mathrm{Ho}$ & $\mathrm{B}-\mathrm{K}-\mathrm{K}$ & P-C-P \\
\hline \multirow[t]{5}{*}{$\mathrm{Li}$} & $P_{i}$ & -18.81 & & & & & \\
\hline & $P^{(0)}$ & 3.50 & & 3.60 & & & 3.74 \\
\hline & $P^{(1)}$ & 25.14 & 15.70 & 16.56 & 15.39 & - & 16.37 \\
\hline & $P^{(2)}$ & -9.83 & -0.39 & 0.04 & -0.28 & - & -1.30 \\
\hline & $P$ & 0 & 0 & 1.39 & -0.10 & - & 0 \\
\hline \multirow[t]{5}{*}{$\mathrm{Na}$} & $P_{i}$ & -8.77 & & & & & \\
\hline & $P^{(0)}$ & 0.39 & & 0.42 & & & 0.45 \\
\hline & $P^{(1)}$ & 9.85 & 10.22 & 8.84 & 8.93 & 9.28 & 9.76 \\
\hline & $P^{(2)}$ & -1.47 & -1.84 & -0.70 & -0.45 & -0.93 & -1.44 \\
\hline & $P$ & 0 & 0 & -0.21 & 0.13 & 0 & 0 \\
\hline \multirow[t]{5}{*}{ K } & $P_{i}$ & -3.75 & & & & & \\
\hline & $P^{(0)}$ & -0.33 & & -0.33 & & & -0.34 \\
\hline & $P^{(1)}$ & 4.52 & 5.12 & 4.22 & 4.53 & 4.51 & 4.53 \\
\hline & $P^{(2)}$ & -0.44 & -1.04 & -0.37 & -0.47 & -0.50 & -0.44 \\
\hline & $P$ & 0 & 0 & -0.23 & -0.02 & -0.07 & 0 \\
\hline \multirow[t]{5}{*}{$\mathrm{Rb}$} & $P_{i}$ & -2.87 & & & & & \\
\hline & $P^{(0)}$ & -0.36 & & -0.36 & & & -0.34 \\
\hline & $P^{(1)}$ & 3.35 & 4.56 & 3.24 & 3.52 & - & 3.47 \\
\hline & $P^{(2)}$ & -0.12 & -1.33 & -0.28 & -0.28 & - & -0.26 \\
\hline & $P$ & 0 & 0 & -0.27 & 0.01 & $\longrightarrow$ & 0 \\
\hline \multirow[t]{5}{*}{$\mathrm{Cs}$} & $P_{i}$ & -2.09 & & & & & \\
\hline & $P^{(0)}$ & -0.35 & & & -0.36 & & -0.30 \\
\hline & $P^{(1)}$ & 2.54 & 3.49 & - & 2.64 & - & 2.59 \\
\hline & $P^{(2)}$ & -0.10 & -1.05 & - & -0.21 & - & -0.20 \\
\hline & $P$ & 0 & 0 & - & -0.02 & - & 0 \\
\hline
\end{tabular}


Table VIII. The individual terms $B_{i}, B^{(0)}, B^{(1)}$ and $B^{(2)}$ contributing to the bulk modulus $\left(10^{11} \mathrm{dyn} \cdot \mathrm{cm}^{-2}\right)$.

\begin{tabular}{rlrrrrrr} 
& & present & A-L & Ho & m.Ho & B-K-K & P-C-P \\
\hline $\mathrm{Li}$ & $B_{i}$ & -2.510 & & & & & \\
& $B^{(0)}$ & 0.977 & & 0.993 & & & 0.968 \\
& $B^{(1)}$ & 5.028 & 3.140 & 3.313 & 3.079 & - & 3.275 \\
& $B^{(2)}$ & -2.249 & -0.424 & -0.499 & -0.254 & - & -0.409 \\
\hline $\mathrm{Na}$ & $B_{i}$ & -1.170 & & & & & \\
& $B^{(0)}$ & 0.253 & & 0.260 & & & 0.256 \\
& $B^{(1)}$ & 1.970 & 2.045 & 1.768 & 1.787 & 1.857 & 1.952 \\
& $B^{(2)}$ & -0.354 & -0.386 & -0.092 & -0.131 & -0.204 & -0.285 \\
\hline $\mathrm{K}$ & $B_{i}$ & -0.500 & & & & & \\
& $B^{(0)}$ & 0.027 & & 0.030 & & & 0.030 \\
& $B^{(1)}$ & 0.904 & 1.024 & 0.844 & 0.907 & 0.901 & 0.908 \\
& $B^{(2)}$ & -0.083 & -0.236 & 0.002 & -0.069 & -0.053 & -0.072 \\
\hline $\mathrm{Rb}$ & $B_{i}$ & -0.383 & & & & & \\
& $B^{(0)}$ & 0.003 & & 0.005 & & & -0.003 \\
& $B^{(1)}$ & 0.671 & 0.913 & 0.647 & 0.704 & - & 0.695 \\
& $B^{(2)}$ & -0.006 & -0.222 & -0.005 & -0.036 & - & -0.027 \\
\hline $\mathrm{Cs} \quad B_{i}$ & -0.279 & & & & & \\
& $B^{(0)}$ & -0.011 & & & -0.010 & & -0.013 \\
& $B^{(1)}$ & 0.510 & 0.700 & - & 0.528 & - & 0.519 \\
& $B^{(2)}$ & 0.025 & -0.167 & - & -0.022 & - & -0.014 \\
\hline
\end{tabular}

\section{§3.2 Third Order Perturbation Term}

Next, we investigate the third order energy $E^{(3)}$ by Lloyd-Sholl ${ }^{2)}$ and by Brovman et al. ${ }^{3)}$. This is that for the simplest loop diagram and is given by

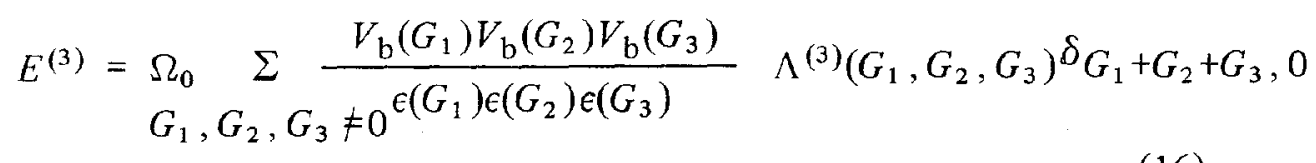

where the details of $\Lambda^{(3)}\left(G_{1}, G_{2}, G_{3}\right)$ are referred to the above original paper. Similarly, we obtain the corresponding third order contributions $P^{(3)}$ and $B^{(3)}$ to the pressure and the bulk modulus according to the definition of eqs.(12) and (13). In Tables IX-XI, we show these contributions together with the ratio of the total quantities. From these tables, we see that third order contributions are not negligible but small except $\mathrm{Li}$ in our model and for 
相馬俊信, 佐藤敏夫, 桜庭 勉, 山平千鶴子, 大山孝清

Table IX. The third order contribution $E^{(3)}$ (in $\mathrm{eV}$ unit) and the ratio to $R_{\mathrm{E}}=E^{(3)} / E_{\mathrm{coh}}$ to the cohesive energy $E_{\mathrm{coh}}$ in the framework of the second order perturbation formalism.

$\begin{array}{llcccccc} & & \text { present } & \mathrm{A}-\mathrm{L} & \text { Ho } & \text { m.Ho } & \text { B-K-K } & \text { P-C-P } \\ \mathrm{Li} & E^{(3)} & 0.21 & 0.03 & 0.00 & 0.00 & - & 0.02 \\ & R_{\mathrm{E}} & 0.11 & 0.02 & 0.00 & 0.00 & - & 0.01 \\ \mathrm{Na} & E^{(3)} & 0.038 & 0.034 & 0.005 & 0.003 & 0.019 & 0.035 \\ & R_{\mathrm{E}} & 0.036 & 0.035 & 0.004 & 0.002 & 0.016 & 0.031 \\ \mathrm{~K} & E^{(3)} & 0.018 & 0.063 & 0.008 & 0.014 & 0.016 & 0.018 \\ & R_{\mathrm{E}} & 0.021 & 0.085 & 0.008 & 0.012 & 0.017 & 0.019 \\ \mathrm{Rb} & E^{(3)} & 0.001 & 0.098 & 0.007 & 0.007 & - & 0.007 \\ & R_{\mathrm{E}} & 0.002 & 0.177 & 0.007 & 0.008 & - & 0.008 \\ \mathrm{Cs} & E^{(3)} & 0.001 & 0.132 & - & 0.007 & - & 0.004 \\ & R_{\mathrm{E}} & 0.002 & 0.229 & - & 0.009 & - & 0.005\end{array}$

Table X. The third order contribution $P^{(3)}$ (in $10^{10} \mathrm{dyn} \cdot \mathrm{cm}^{-2}$ unit) and the ratio $\left|R_{\mathrm{p}}=P^{(3)} / P^{(2)}\right|$ to the pressure $P^{(2)}$ in the second order contribution.

$\begin{array}{llllllll} & & \text { present } & \text { A-L } & \text { Ho } & \text { m.Ho } & \text { B-K-K } & \text { P-C-P } \\ \mathrm{Li} & P^{(3)} & 2.68 & 0.06 & 0.00 & 0.03 & - & 0.21 \\ & R_{\mathrm{p}} & 0.27 & 0.15 & 0.10 & 0.11 & - & 0.16 \\ \mathrm{Na} & P^{(3)} & 0.39 & 0.53 & 0.07 & 0.05 & 0.24 & 0.37 \\ & R_{\mathrm{p}} & 0.27 & 0.29 & 0.10 & 0.11 & 0.26 & 0.26 \\ \mathrm{~K} & P^{(3)} & 0.09 & 0.44 & 0.06 & 0.07 & 0.08 & 0.08 \\ & R_{\mathrm{p}} & 0.20 & 0.42 & 0.17 & 0.14 & 0.16 & 0.19 \\ \mathrm{Rb} & P^{(3)} & 0.01 & 0.63 & 0.04 & 0.03 & - & 0.03 \\ & R_{\mathrm{p}} & 0.11 & 0.47 & 0.13 & 0.10 & - & 0.11 \\ \mathrm{Cs} & P^{(3)} & 0.01 & 0.56 & - & 0.02 & - & 0.01 \\ & R_{\mathrm{p}} & 0.09 & 0.53 & - & 0.09 & - & 0.07\end{array}$


Table XI. The third order contribution $B^{(3)}$ (in $10^{11} \mathrm{dyn} \cdot \mathrm{cm}^{-2}$ ) and the ratio $\left|R_{\mathrm{B}}=B^{(3)} / B\right|$ to the bulk modulus $B$ in the framework of the second order perturbation formalism.

$\begin{array}{llllllll} & & \text { present } & \text { A-L } & \text { Ho } & \text { m.Ho } & \text { B-K-K } & \text { P-C-P } \\ \mathrm{Li} & B^{(3)} & 0.212 & 0.058 & 0.049 & 0.026 & - & 0.079 \\ & R_{\mathrm{B}} & 0.17 & 0.05 & 0.04 & 0.02 & - & 0.06 \\ \mathrm{Na} & B^{(3)} & 0.064 & 0.077 & 0.018 & 0.014 & 0.051 & 0.064 \\ & R_{\mathrm{B}} & 0.09 & 0.10 & 0.02 & 0.02 & 0.07 & 0.09 \\ \mathrm{~K} & B^{(3)} & 0.005 & 0.055 & 0.008 & 0.005 & 0.007 & 0.006 \\ & R_{\mathrm{B}} & 0.02 & 0.18 & 0.02 & 0.01 & 0.02 & 0.02 \\ \mathrm{Rb} & B^{(3)} & 0.002 & 0.038 & 0.005 & 0.007 & - & 0.006 \\ & R_{\mathrm{B}} & 0.01 & 0.12 & 0.02 & 0.03 & - & 0.02 \\ \mathrm{Cs} & B^{(3)} & -0.000 & 0.022 & - & -0.003 & - & -0.002 \\ & R_{\mathrm{B}} & 0.01 & 0.09 & - & 0.02 & - & 0.01\end{array}$

Ashcroft-Langreth model. This result is consistent with previous work for $\mathrm{Na}$ (see for example ${ }^{7)}$ ), and third order contributions seem to be important for polyvalent metal with the covalent force such as $\mathrm{In}, \mathrm{Sn}$ and $\mathrm{Pb}$.

In conclusion, we presented a local Heine-Abarenkov-type model potential of alkali metals using the original pseudopotential proposed by Animalu and Heine, and obtained the numerical results of cohesive energy and bulk modulus in good agreement with the observed data. This potential will be useful to the studies for the anharmonicity of lattice dynamics, the problem of the alloy system and the complicated lattice defects.

\section{Acknowledgement}

The authors would like to thank Messrs. Masaki SAGA, Satoshi ITOH and Tsukasa SARUTA for helps in part of the programming work and in preparing the final manuscript. 
相馬俊信, 佐藤敏夫, 桜庭 勉, 山平千鶴子, 大山孝清

\section{References}

1) V. Heine and D. L. Weaire, Solid State Phys. 24 (1970) 249.

2) P. Lloyd and C. A. Sholl, J. Phys. C 2 (1968) 1620.

3) E. G. Brovman, Yu. Kagan and A. Kholas, Soviet Phys. - JETP - 34 (1972) 394.

4) A. R. Williams, J. Phys. F 3 (1973) 781.

5) R. E. Molaren and C. A. Sholl, J. Phys. F 4 (1974) 2172.

6) C. M. Bertoni, V. Bortolani, C. Calandra and F. Nizzoli, J. Phys. F 4 (1974) 19; ibid 5 (1975) 419.

7) S. Benckert, Phys. Stat. Sol. (b) 68 (1975) 483.

8) D. G. Garret and J. C. Swihart, J.Phys. F 6 (1976) 1781.

9) N. W. Ashcroft, Phys. Letters 23 (1966) 48.

10) R.W. Shaw, Phys. Rev. B 5 (1972) 4742.

11) N. W. Ashcroft and D. C. Langreth, Phys. Rev. 155 (1967) 682.

12) P.S. Ho, Phys. Rev. 169 (1968) 523.

13) P. S. Ho, Phys. Rev. B 3 (1971) 4035.

14) E. G. Brovman, Yu. Kagan and A. Kholas, Soviet Phys. - Solid State - 12 (1970) 786.

15) Z. D. Popovic, J.P. Carbotte and G. R. Piergy, J. Phys. F 4 (1974) 351.

16) M. Senoo, H. Mii and I. Fujishiro, J. Phys. Soc. Japan 41 (1976) 1562.

17) J. Hubbard, Proc. Roy. Soc. A 243 (1957) 336.

18) K. S. Singwi, A. S. Sjölander, M. P. Tosi and R. H. Land, Phys. Rev. B 1 (1970) 1044.

19) L. J. Sham, Proc. Roy. Soc. A 283 (1965) 33.

20) W. A. Harrison, Pseudopotentials in the Theory of Metals (Benjamin, New York) (1966) 310.

21) L. Kleinman, Phys. Rev. 160 (1967) 585; D. C. Langreth, Phys. Rev. 181 (1969) 753.

22) P. Nozières and D. Pines, Phys. Rev. 111 (1958) 442.

23) P. Vashishta and K. S. Singwi, Phys. Rev. B 6 (1972) 875.

24) C. Kittel, Introduction to Solid State Physics (John Wiley and Sons, New York) 5th ed. (1976).

25) T. Soma, J. Phys. Soc. Japan 36 (1974) 1292. 